\title{
Renoprotection by Remote Ischemic Conditioning During Elective Coronary Revascularization: A Systematic Review and Meta-Analysis of Randomized Controlled Trials
}

Chenghui Zhou ${ }^{1}$,M.D, Ph.D, Yunseok Jeon', M.D,Ph.D, Patrick Meybohm³, M.D, Ph.D, Alexander Zarbock ${ }^{4}$, M.D, Paul Jeffrey Young ${ }^{5}$, M.D, Lihuan Li $^{1 *}$,M.D, Ph.D, Derek J Hausenloy $^{6,7,8,9}$, Ph.D, FRCP, FACC, FESC

${ }^{1}$ Department of Anesthesiology, State Key Laboratory of Cardiovascular Disease, Fuwai Hospital, National Center for Cardiovascular Diseases, Chinese Academy of Medical Sciences and Peking Union Medical College, Beijing, 100037, China

${ }^{2}$ Department of Anesthesiology and Pain Medicine, Seoul National University Hospital, Daehakro 101 Seoul 110-744, South Korea

${ }^{3}$ Department of Anesthesiology, Intensive Care Medicine, and Pain Therapy, University Hospital Frankfurt, Theodor-Stern-Kai 7, 60590 Frankfurt, Germany

${ }^{4}$ Department of Anesthesiology, Critical Care Medicine and Pain Therapy, University Hospital Münster, AlbertSchweitzer-Campus 1, Gebäude A1, 48149 Münster, Germany

${ }^{5}$ Wellington Hospital, Capital and Coast District Health Board, Private Bag 7902, Wellington 6242, New Zealand

${ }^{6}$ The Hatter Cardiovascular Institute, University College London, 67 Chenies Mews, London WC1E 6HX, United Kingdom

${ }^{7}$ The National Institute of Health Research University College London Hospitals Biomedical Research Centre, London, United Kingdom

${ }^{8}$ National Heart Research Institute Singapore, National Heart Centre Singapore, Singapore

${ }^{9}$ Cardiovascular and Metabolic Disorders Program, Duke-National University of Singapore, Singapore

* Corresponding Author:

Tel: 86-10-88398184, Fax: 86-10-88398184, E-mail:1lhfw59@163.com (Lihuan Li)

Address: No. 167 Beilishi Road, Xicheng District, Beijing, 100037, China

Running title: Remote conditioned renal effect in CAD procedures

Funding sources: This work was supported by the National Natural Science Foundation of China [grant number 81400271], and the Clinical Research Foundation of Fuwai Hospital [no.2016-ZX09].

Conflict of Interest: None declared.

Keywords remote ischemic conditioning, renoprotection, coronary artery bypass graft, percutaneous coronary intervention 
Background Remote ischemic conditioning(RIC) has been recognized an emerging non-invasive approach for preventing acute kidney injury(AKI) in patients undergoing either elective coronary artery bypass graft (CABG) surgery or percutaneous coronary intervention (PCI). On the other hand, accumulating evidence have indicated the involving role of pre-CABG contrast usage for coronary angiography in post-surgery AKI risk. Along with the shortening time delay of CABG after coronary angiography, and the prevalent hybrid coronary revascularization(HCR), the AKI prevention by RIC has faced challenges following coronary revascuralization.

Methods Randomized controlled trials (RCTs) were searched from Pubmed, EMBase, and Cochrane library (until May 2016). The primary outcome was postoperative AKI. The second outcomes included the requirement for renal replacement therapy(RRT), and in-hospital or 30-day mortality.

Results Twenty eligible RCTs (CABG, 3357 patients; PCI, 1501 patients) were selected. RIC significantly halved the incidence of AKI following PCI when compared with controls[n=1501; odds ratio $(\mathrm{OR})=0.51 ; 95 \% \mathrm{CI}, 0.32$ to $0.82 ; \mathrm{P}=0.006 ; \mathrm{I} 2=29.6 \%$. However, $\mathrm{RIC}$ did not affect the incidence of AKI following CABG ( $\mathrm{n}=1850 ; \mathrm{OR}=0.94 ; 95 \%$ CI, 0.73 to $1.19 ; \mathrm{P}=0.586 ; \mathrm{I} 2=12.4 \%)$. The requirement for RRT and in-hospital mortality were not affected by RIC in CABG $(\mathrm{n}=2049, \mathrm{OR}=1.04, \mathrm{P}=0.87 ; \mathrm{n}=1920, \mathrm{OR}=0.89, \mathrm{P}=0.7$; respectively $)$.

Conclusions Our meta-analysis suggests that RIC for preventing AKI following CABG has faced with challenges in terms of AKI, the requirement for RRT, and mortality. However, RIC shows a renoprotective benefit for PCI. Hence, our findings may infer the preserved renal effects of RIC in CABG with preconditioning before the coronary angiography, or in HCR. 


\section{Introduction}

Acute kidney injury (AKI) following elective coronary artery bypass graft (CABG) surgery occurs up to $45 \%$ of patients and it is associated with increased medium- and long-term cardiovascular morbidity and mortality[1-5]. AKI after CABG has been attributed to reduced renal blood flow by cardiopulmonary bypass $[6,7]$ and hemodynamic instability. Contrast agent, regularly 
used in percutaneous coronary intervention (PCI) [8-10], may also contribute to the risk of postoperative $\mathrm{AKI}$ in $\mathrm{CABG}$ patients undergoing pre-surgery coronary angiography[11-13]. This is an important issue given the shortening in the time interval between coronary angiography and CABG[11-13], and the increasing use of hybrid coronary revascularization(HCR) for multi-vessel coronary artery disease (CAD) $[14,15]$. Therefore, novel strategies are needed to prevent AKI in patients undergoing CABG surgery.

In 1993, Przyklenk et al[16] first demonstrated that regional ischemic preconditioning protected remote virgin myocardium of dogs against subsequent sustained coronary artery occlusion and reflow, implying the release of protective factors which can be transported to other organs to increase ischemic tolerance. This phenomenon has been termed 'remote ischemic preconditioning' (RIPC), and it can be induced non-invasively by simply inflating and deflating a standard blood pressure cuff placed on the upper arm or thigh. Experimental studies have shown that RIC confers renoprotection against acute ischemia/reperfusion (I/R) injury in numerous animal models[17-20]. Whether perioperative RIC can reduce the incidence of AKI in patients undergoing elective CABG remain unclear.

Both single and multi-centre randomized controlled trials(RCT) have investigated the renal effect of RIC in the setting of CABG, but the results have been mixed[21-23] [24-26]. In contrast, evidence supporting the use of RIC as a renoprotective strategy in patients undergoing elective percutaneous coronary intervention (PCI) is increasing[27, 28], suggesting that RIPC may be beneficial in those patients undergoing pre-CABG coronary angiography or those undergoing PCI as a part of HCR strategy. Hence, we sought to comprehensively summarize the evidence for renoprotection of RIC both in CABG and PCI to highlight future opportunities for the use of RIC in the setting of CABG surgery.

\section{Methods}




\section{Search strategy and study criteria}

We searched English-published RCTs in PubMed, EMBase, and Cochrane Library (up to April 2016), and scientific sessions (2012 2015) of American Heart Association (AHA), American College of Cardiology(ACC), and European Society of Cardiology (ESC) using keywords "remote ischemic conditioning", "coronary artery bypass graft", "percutaneous coronary intervention", "coronary revascularization", "kidney", and "renal". Invasive procedures were defined as elective CABG or PCI. Exclusion criteria were: (1) studies not reporting one of the following endpoints: AKI and renal replacement therapy (RRT), and (2) primary PCI.

\section{Literature review and data extraction}

The literature review and data extraction were independently completed by two investigators (Y.L. and H.P). Discussion was conducted for consensus in case of discrepancies. Quality assessment was completed according to the Jadad score: randomization; blinding; withdrawals and dropouts (a possible score between 0 and 5). Trials with a score of more than 3 were considered to be high-quality[29]. Data extraction included baseline patient characteristics (age, male, diabetes, history of MI, dyslipidemia, hypertension, baseline left ventricular ejection fraction, target vessels $\geq 2, \beta$-blockers usage, statins usage) as well as information pertaining to the RIC protocol (number cycles, ischemic time, and which limb), and follow-up time.

\section{Postoperative Outcomes and Definitions}

The primary endpoints was incidence of AKI within 7 days after CABG or PCI, defined as follows: (1) a relative increase of $>50 \%$ or an absolute increase of $>0.3 \mathrm{mg} / \mathrm{dL}$ in serum creatinine from baseline, (2) a relative increase of $\geq 25 \%$ or an absolute increase of $\geq 0.5 \mathrm{mg} / \mathrm{dL}$ in serum creatinine from baseline, (3) a relative decrease in estimated glomerular filtration rate $>25 \%$ from baseline, (4) urinary liver-type fatty acid-binding protein (L-FABP) levels $>17.4 \mu \mathrm{g} / \mathrm{g}$ serum creatinine levels]. 
The secondary outcomes includes in-hospital RRT, and all-cause mortality(in-hospital or within 30 days).

\section{Statistical analysis}

For dichotomous ones (reported with incidence), we calculated odds ratio (OR) with $95 \%$ confidence interval (CI). Random-effect model was used for the pooled analysis in the consideration of potential clinical inconsistency. The study with no event occurred in either of the two (treated or untreated) groups was excluded from the pooled analysis. When only one group of the study contained no events, a fixed value(0.5) was added to each cell of the $2 \mathrm{X} 2$ table for the pooled analysis. Publication bias was assessed by Begg's test and Egger's test for AKI. Sensitivity analyses were used to evaluate the robustness of our results by removing each included study at one time to obtain and assess the remaining overall estimates of AKI. Meta-regression and subgroup analyses were performed to explore the potential sources of heterogeneity and a P value of less than 0.1 was accepted. $P<0.05$ (2-sided) was considered to be statistically significant for hypothesis testing. All statistical analyses were performed in Stata(version 11.0; Stata Corporation, College Station, TX).

\section{Results}

\section{Study characteristics}

After 2119 abstracts were excluded from initial search due to duplication, review, experimental design, and other irrelevant content, Seventy-four potential studies were selected for detailed evaluation. Fifty-four studies were further excluded for the following reasons: valve surgery $(n=7)$, vascular surgery $(n=6)$, pediatric surgery $(n=11)$, primary $\operatorname{PCI}(n=9)$, irretrievable or unclear data $(n=3)$, nonrenal endpoints $(n=10)$, ongoing trial $(n=2)$, and endothelial trials $(n=6)$. Twenty trials[21-28, 30-36]'[37-41] with a total of 4858 patients ( $n=2471$ in RIC group) ultimately met our selection criteria, eleven[21-26, 30, 31, 34-36] of which were conducted for 3357 subjects in 
elective CABG (Figure 1). The ischemic protocol (cycles $\times \mathrm{I} / \mathrm{R})$ was $2 \sim 4 \times 5 \mathrm{~min} / 5 \mathrm{~min}$ in nineteen studies[21-26, 28, 30-36]'[37-41], and $4 \times 30$ s/30s in one[27]. The upper limb was used in fifteen studies[21-23, 25, 26, 28, 30-33]'[37-41], the thigh in three[24, 34, 35], the combination of upper limb and thigh in one[36], and the heart in one[27]. The time interval between first cuff for remote conditioning to coronary reflow was 30 157 $\mathrm{min}$ in CABG, and several to $120 \mathrm{~min}$ in PCI. Perioperative AKI was reported in seventeen studies[21-25, 27, 28, 30-33, 36]'[37-41], RRT in ten [21-23, 25, 26, 30, 31, 34-36], and mortality in eight[21-23, 25, 26, 30, 31, 35].Seventeen studies

$[21,22,24-28,30-36][37,40,41]$ had a Jadad score $\geq 3$. Study design and patient characteristics are summarized in Table 1 and 2.

\section{Effect of RIC on the incidence of AKI}

The incidence of AKI following CABG was 31.4\% ( $n=8$ studies; RIC: 286/925;Control: 295/925) and 9.1\% in PCI ( $\mathrm{n}=9$ studies; RIC: 51/814;Control: 96/796). RIC lowered the risk of $\mathrm{AKI}$ in patients undergoing $\mathrm{PCI}(\mathrm{OR}=0.51 ; 95 \% \mathrm{CI}, 0.32$ to $0.82 ; \mathrm{P}=0.006 ; \mathrm{I} 2=29.6 \%)$ but not in CABG $(\mathrm{OR}=0.96 ; 95 \% \mathrm{CI}, 0.76$ to $1.20 ; \mathrm{P}=0.695 ; \mathrm{I} 2=6.8 \%)$ (Figure $2 \mathrm{~A}$ and $2 \mathrm{~B})$.

The AKI stage I was reported in $1142 \mathrm{CABG}$ patients with an overall incidence of $22.7 \%(\mathrm{n}=6$ studies; RIC:128/583; Control: 131/559). RIC did not reduce the incidence of AKI stage I (OR= $0.80 ; 95 \% \mathrm{CI}, 0.49$ to $1.31 ; \mathrm{P}=0.377 ; \mathrm{I} 2=27.4 \%$ )(Figure $3 \mathrm{~A})$.

\section{Effect of RIC on the Requirement for RRT and Mortality}

The in-hospital RRT was reported in 2049 study subjects undergoing CABG, and the overall incidence was 3.1\% ( $\mathrm{n}=10$ studies; RIC: 32/1033;Control: 31/1016). The requirement forpostoperative RRT was not reduced by RIC intervention( $\mathrm{OR}=1.04 ; 95 \% \mathrm{CI}, 0.62$ to 1.76 ; $\mathrm{P}=0.87$; $\mathrm{I} 2=0.0 \%)($ Figure 3B).

Mortality was reported in 1920 study subjects for CABG cohort, and the overall incidence was 1.8\% (n=8; RIC:17/972; Control:18/948). Mortality was nonsignificantly reduced with RIC 
compared with control $(\mathrm{OR}=0.89,95 \% \mathrm{CI}: 0.45$ to $1.76, \mathrm{P}=0.74$ : I2=0.0\%)(Figure 4) .

\section{Potential Sources of Heterogeneity}

Age, male (\%), history of MI, diabetes (\%), hypertension (\%), dyslipidaemia (\%), contrast volume (ml), $\beta$-blockers(\%), statins(\%), and additive duration of ischemic conditioning(cycles time ischemic duration, min)were included in the random-effect univariate meta-regression analysis for AKI in PCI. As a result, the identified major sources of heterogeneity was additive duration of ischemic conditioning $(\min )($ coefficient $=-0.22 ; \quad \mathrm{P}=0.057$; adjusted $\mathrm{R} 2=1.00)$ for $\mathrm{AKI}$. When compared with the 15-min subgroup, the 20-min subgroup demonstrated a significant reduction in the incidence of AKI levels [OR: $0.26(\mathrm{P}=0.001)$ vs. $0.80(\mathrm{P}=0.42) ; \mathrm{P}=0.02$ for subgroup difference].

\section{Discussion}

In the present meta-analysis of 20 randomized trials enrolling $4858 \mathrm{CAD}$ patients undergoing elective coronary revascularization, we found that RIC may offer renoprotection by reducing in-hospital AKI, especially in PCI. Moreover, increase in the number of RIC cycles may improve the clinical benefit for renal function by RIC. However, the effect of RIC on the requirement for RRT and mortality merits further investigations.

Revascularization type. Up to now, $\mathrm{CABG}$ and PCI remain two key therapeutic options for treating patients with stable CAD, and both are associated with substantial risk of AKI. There has always been a concern whether renoprotective therapies established in PCI can be translated into the setting of CABG. Clinical studies investigating periprocedural use of statins[6, 42], $\mathrm{N}$-acetylcysteine[43, 44], sodium bicarbonate[45, 46], and erythropoietin[47, 48] have produced neutral results. In our meta-analysis,a higher rate of AKI in CABG (35.1\% vs $9.1 \%$ in PCI) was observed, and the absolute risk reduction of post-procedural AKI by RIC was $0.8 \%$ in CABG and $5.8 \%$ in PCI. This discrepancy may due to differences in the mechanisms of acute renal 
injury(cardiopulmonary bypass and low $\mathrm{CO}$ in CABG versus contrast in PCI) [8-10], potential interference of volatile anesthetics[49], and higher rate of blood product transfusion during CABG[50]. Future studies should help elucidate the differential effects of RIC on renal injury.

Optimal conditioning protocol. In the meta-analysis, the most widely used RIC protocol was 2 4 cycles of 5-min ischemia and reperfusion intervals of one unilateral limb achieved using a blood pressure cuff(inflated to $\geq 200 \mathrm{mmHg}$ or $50 \mathrm{mmHg}>\mathrm{SBP}$ ). However, whether optimization in RIC protocol algorithm could confer renoprotective benefits remains unknown-for example combined conditioning in two remote organs[36], increase in the number of cycles, or a prolonged ischemic interval. In our investigation, the additive duration for ischemic conditioning in PCI is $15 \mathrm{~min}$ in six studies and $20 \mathrm{~min}$ in three one. Further regression analysis showed that additive duration was negatively correlated with risk of $\mathrm{AKI}(\mathrm{Ln}$-transformation), reducing by 0.22 per 1 min increase. This first intriguing indication for renal protection may provide some suggestion in the clinical setting of RIC.

Optimal timing, new concept and clinical implication. It is also unknown how long RIC should be initiated before coronary revascularization to achieve renal benefit. RIC has been shown to elicit the protective effect in 2 different phases: early phase ( $<4$ hours) and delayed phase (24 72hours)[51]. The time window in our analysis is quite wide-ranging (CABG, $30 \sim 157$ min; PCI , several 120 min). In our subgroup analysis, a dramatic difference in the effect of RIC on postprocedural AKI between CABG and PCI was obtained. How to improve the renal effect of RIC in patients undergoing $\mathrm{CABG}$ is an interesting issue. Recently, the pivotal role of time interval between coronary angiography and CABG surgery in postoperative AKI has been proposed in several large retrospective adjusted analyses[11-13]. The risk of AKI was highest in whom CABG was performed $\leqslant 1$ day after cardiac catheterization, indicating that the underlying mechanisms of postprocedural AKI may be complicated with pre-existed contrast-induced injury. Based on these 
evidence, the optimal timing for the reduction in CABG-associated $\mathrm{AKI}$ is a question that needs comprehensive consideration. The initiation of RIC before coronary angiography in patients waiting for CABG may be a new concept for preventing AKI in clinical practice.

HCR has become a popular choice for its potential clinical benefit in selected patient with multivessel CAD. Although the off-pump technique itself has shown to provide better preservation of renal function than on-pump CABG $[52,53]$, AKI may be aggravated by simultaneous coronary angiography. Wang et al[54] using a propensity-matched analysis found a higher incidence of AKI in the hybrid group than that in the off-pump $\mathrm{CABG}(25.2 \%$ vs $17.6 \%)$. Our pooled analysis could add the potential renal evidence of translation for RIC in HCR in the future.

Strengths and Limitations. The strengths of this meta analysis include the main concern for renal outcomes, clinical sufficient consistency(restricted type of invasive procedures), and its ability in garnering a new large study population. On the other hand, several limitations should be pointed out for this study. Firstly, the potential influences of other co-morbidities (such as age, diabetes, and contrast volume)[27] and cardiovascular medications (such as $\beta$-blocker[55] ) may be

underestimated. Secondly, the definitions for AKI varied trial from trial. Thirdly, AKI has been used as a surrogate endpoint to assess efficacy of RIC. However, there was no trend towards benefit with RIC in the hard renal outcomes such as hemodialysis or death. Lastly, the effect of RIC on long-term cardiovascular morbidity and mortality in elective coronary revascularization still need further evidence in future clinical trials.

\section{Conclusions}

Our meta-analysis suggests that RIC does not offer renoprotection during CABG surgery in terms of preventing AKI, reducing the requirement for RRT, and mortality. However, our study does show the renoprotective effect of RIPC in preventing AKI in patients undergoing elective PCI. Hence, our findings may infer the preserved renal effects of RIC in CABG with preconditioning 
before the coronary angiography, or in HCR

\section{Acknowledgement:}

The author thanks two colleagues from Fuwai hospital: Dr Hanjun Pei and Dr Yuehua Li for their literature assistant. We also appreciate the informative data from : Professor Yunseok Jeon(South Korea), Professor Derek J Hausenloy(UK), Professor Patrick Meybohm(German), Professor Alexander Zarbock(German), and Professor Paul Young(New Zealand).

\section{References}

[1] Hobson CE, Yavas S, Segal MS, Schold JD, Tribble CG, Layon AJ, et al. Acute kidney injury is associated with increased long-term mortality after cardiothoracic surgery. Circulation. 2009;119:2444-53. 
[2] Koyner JL, Bennett MR, Worcester EM, Ma Q, Raman J, Jeevanandam V, et al. Urinary cystatin C as an early biomarker of acute kidney injury following adult cardiothoracic surgery. Kidney international. 2008;74:1059-69.

[3] Rihal CS, Textor SC, Grill DE, Berger PB, Ting HH, Best PJ, et al. Incidence and prognostic importance of acute renal failure after percutaneous coronary intervention. Circulation. 2002;105:2259-64.

[4] Lindsay J, Apple S, Pinnow EE, Gevorkian N, Gruberg L, Satler LF, et al. Percutaneous coronary intervention-associated nephropathy foreshadows increased risk of late adverse events in patients with normal baseline serum creatinine. Catheterization and cardiovascular interventions : official journal of the Society for Cardiac Angiography \& Interventions. 2003;59:338-43.

[5] Best PJ, Lennon R, Ting HH, Bell MR, Rihal CS, Holmes DR, et al. The impact of renal insufficiency on clinical outcomes in patients undergoing percutaneous coronary interventions. Journal of the American College of Cardiology. 2002;39:1113-9.

[6] Mithani S, Kuskowski M, Slinin Y, Ishani A, McFalls E, Adabag S. Dose-dependent effect of statins on the incidence of acute kidney injury after cardiac surgery. The Annals of thoracic surgery. 2011;91:520-5.

[7] Chew S, Ng R, Liu W, Goh SG, Caleb MG, Ti LK. Miniaturized versus conventional cardiopulmonary bypass and acute kidney injury after cardiac surgery. Perfusion. 2016;31:60-7.

[8] Tehrani S, Laing C, Yellon DM, Hausenloy DJ. Contrast-induced acute kidney injury following PCI. European journal of clinical investigation. 2013;43:483-90.

[9] Evans RG, Ince C, Joles JA, Smith DW, May CN, O'Connor PM, et al. Haemodynamic influences on kidney oxygenation: clinical implications of integrative physiology. Clinical and experimental pharmacology \& physiology. 2013;40:106-22.

[10] Goren O, Matot I. Perioperative acute kidney injury. British journal of anaesthesia. 2015;115 Suppl 2:ii3-ii14.

[11] Mehta RH, Honeycutt E, Patel UD, Lopes RD, Williams JB, Shaw LK, et al. Relationship of the time interval 
between cardiac catheterization and elective coronary artery bypass surgery with postprocedural acute kidney injury. Circulation. 2011;124:S149-55.

[12] Lee EH, Chin JH, Joung KW, Choi DK, Kim WJ, Lee JB, et al. Impact of the time of coronary angiography on acute kidney injury after elective off-pump coronary artery bypass surgery. The Annals of thoracic surgery. 2013;96:1635-41.

[13] Mariscalco G, Cottini M, Dominici C, Banach M, Piffaretti G, Borsani P, et al. The effect of timing of cardiac catheterization on acute kidney injury after cardiac surgery is influenced by the type of operation. International journal of cardiology. 2014;173:46-54.

[14] Shen L, Hu S, Wang H, Xiong H, Zheng Z, Li L, et al. One-stop hybrid coronary revascularization versus coronary artery bypass grafting and percutaneous coronary intervention for the treatment of multivessel coronary artery disease: 3-year follow-up results from a single institution. Journal of the American College of Cardiology. 2013;61:2525-33.

[15] Harskamp RE, Bagai A, Halkos ME, Rao SV, Bachinsky WB, Patel MR, et al. Clinical outcomes after hybrid coronary revascularization versus coronary artery bypass surgery: a meta-analysis of 1,190 patients. American heart journal. 2014;167:585-92.

[16] Przyklenk K, Bauer B, Ovize M, Kloner RA, Whittaker P. Regional ischemic 'preconditioning' protects remote virgin myocardium from subsequent sustained coronary occlusion. Circulation. 1993;87:893-9.

[17] Park KM, Chen A, Bonventre JV. Prevention of kidney ischemia/reperfusion-induced functional injury and JNK, p38, and MAPK kinase activation by remote ischemic pretreatment. The Journal of biological chemistry. 2001;276:11870-6.

[18] Park KM, Kramers C, Vayssier-Taussat M, Chen A, Bonventre JV. Prevention of kidney ischemia/reperfusion-induced functional injury, MAPK and MAPK kinase activation, and inflammation by remote transient ureteral obstruction. The Journal of biological chemistry. 2002;277:2040-9.

[19] Ates E, Genc E, Erkasap N, Erkasap S, Akman S, Firat P, et al. Renal protection by brief liver ischemia in 
rats. Transplantation. 2002;74:1247-51.

[20] Crowley LE, McIntyre CW. Remote ischaemic conditioning-therapeutic opportunities in renal medicine. Nature reviews Nephrology. 2013;9:739-46.

[21] Rahman IA, Mascaro JG, Steeds RP, Frenneaux MP, Nightingale P, Gosling P, et al. Remote ischemic preconditioning in human coronary artery bypass surgery: from promise to disappointment? Circulation. 2010;122:S53-9.

[22] Venugopal V, Laing CM, Ludman A, Yellon DM, Hausenloy D. Effect of remote ischemic preconditioning on acute kidney injury in nondiabetic patients undergoing coronary artery bypass graft surgery: a secondary analysis of 2 small randomized trials. American journal of kidney diseases : the official journal of the National Kidney Foundation. 2010;56:1043-9.

[23] Gallagher SM, Jones DA, Kapur A, Wragg A, Harwood SM, Mathur R, et al. Remote ischemic preconditioning has a neutral effect on the incidence of kidney injury after coronary artery bypass graft surgery. Kidney international. 2015;87:473-81.

[24] Hong DM, Lee EH, Kim HJ, Min JJ, Chin JH, Choi DK, et al. Does remote ischaemic preconditioning with postconditioning improve clinical outcomes of patients undergoing cardiac surgery? Remote Ischaemic Preconditioning with Postconditioning Outcome Trial. Eur Heart J. 2014;35:176-83.

[25] Hausenloy DJ, Candilio L, Evans R, Ariti C, Jenkins DP, Kolvekar S, et al. Remote Ischemic Preconditioning and Outcomes of Cardiac Surgery. The New England journal of medicine. 2015;373:1408-17. [26] Meybohm P, Bein B, Brosteanu O, Cremer J, Gruenewald M, Stoppe C, et al. A Multicenter Trial of Remote Ischemic Preconditioning for Heart Surgery. The New England journal of medicine. 2015;373:1397-407.

[27] Deftereos S, Giannopoulos G, Tzalamouras V, Raisakis K, Kossyvakis C, Kaoukis A, et al. Renoprotective effect of remote ischemic post-conditioning by intermittent balloon inflations in patients undergoing percutaneous coronary intervention. Journal of the American College of Cardiology. 2013;61:1949-55. [28] Lavi S, D'Alfonso S, Diamantouros P, Camuglia A, Garg P, Teefy P, et al. Remote ischemic postconditioning 
during percutaneous coronary interventions: remote ischemic postconditioning-percutaneous coronary intervention randomized trial. Circulation Cardiovascular interventions. 2014;7:225-32.

[29] Jadad AR, Moore RA, Carroll D, Jenkinson C, Reynolds DJ, Gavaghan DJ, et al. Assessing the quality of reports of randomized clinical trials: is blinding necessary? Controlled clinical trials. 1996;17:1-12.

[30] Zarbock A, Schmidt C, Van Aken H, Wempe C, Martens S, Zahn PK, et al. Effect of remote ischemic preconditioning on kidney injury among high-risk patients undergoing cardiac surgery: a randomized clinical trial. JAMA : the journal of the American Medical Association. 2015;313:2133-41.

[31] Young PJ, Dalley P, Garden A, Horrocks C, La Flamme A, Mahon B, et al. A pilot study investigating the effects of remote ischemic preconditioning in high-risk cardiac surgery using a randomised controlled double-blind protocol. Basic research in cardiology. 2012;107:256.

[32] Hoole SP, Heck PM, Sharples L, Khan SN, Duehmke R, Densem CG, et al. Cardiac remote ischemic preconditioning in coronary stenting (CRISP Stent) study: a prospective, randomized control trial. Circulation. 2009;119:820-7.

[33] Igarashi G, Iino K, Watanabe H, Ito H. Remote ischemic pre-conditioning alleviates contrast-induced acute kidney injury in patients with moderate chronic kidney disease. Circulation journal : official journal of the Japanese Circulation Society. 2013;77:3037-44.

[34] Lucchinetti E, Bestmann L, Feng J, Freidank H, Clanachan AS, Finegan BA, et al. Remote ischemic preconditioning applied during isoflurane inhalation provides no benefit to the myocardium of patients undergoing on-pump coronary artery bypass graft surgery: lack of synergy or evidence of antagonism in cardioprotection? Anesthesiology. 2012;116:296-310.

[35] Hong DM, Jeon Y, Lee CS, Kim HJ, Lee JM, Bahk JH, et al. Effects of remote ischemic preconditioning with postconditioning in patients undergoing off-pump coronary artery bypass surgery--randomized controlled trial. Circulation journal : official journal of the Japanese Circulation Society. 2012;76:884-90.

[36] Candilio L, Malik A, Ariti C, Barnard M, Di Salvo C, Lawrence D, et al. Effect of remote ischaemic 
preconditioning on clinical outcomes in patients undergoing cardiac bypass surgery: a randomised controlled clinical trial. Heart (British Cardiac Society). 2015;101:185-92.

[37] Xu X, Zhou Y, Luo S, Zhang W, Zhao Y, Yu M, et al. Effect of Remote Ischemic Preconditioning in the Elderly Patients With Coronary Artery Disease With Diabetes Mellitus Undergoing Elective Drug-Eluting Stent Implantation. Angiology. 2013;65:660-6.

[38] Savaj S, Savoj J, Jebraili I, Sezavar SH. Remote ischemic preconditioning for prevention of contrast-induced acute kidney injury in diabetic patients. Iranian journal of kidney diseases. 2014;8:457-60. [39] Menting TP, Sterenborg TB, de Waal Y, Donders R, Wever KE, Lemson MS, et al. Remote Ischemic Preconditioning To Reduce Contrast-Induced Nephropathy: A Randomized Controlled Trial. European journal of vascular and endovascular surgery : the official journal of the European Society for Vascular Surgery. 2015;50:527-32.

[40] Luo SJ, Zhou YJ, Shi DM, Ge HL, Wang JL, Liu RF. Remote ischemic preconditioning reduces myocardial injury in patients undergoing coronary stent implantation. The Canadian journal of cardiology. 2013;29:1084-9. [41] Er F, Nia AM, Dopp H, Hellmich M, Dahlem KM, Caglayan E, et al. Ischemic preconditioning for prevention of contrast medium-induced nephropathy: randomized pilot RenPro Trial (Renal Protection Trial). Circulation. 2012;126:296-303.

[42] Hoshi T, Sato A, Kakefuda Y, Harunari T, Watabe H, Ojima E, et al. Preventive effect of statin pretreatment on contrast-induced acute kidney injury in patients undergoing coronary angioplasty: propensity score analysis from a multicenter registry. International journal of cardiology. 2014;171:243-9.

[43] Adabag AS, Ishani A, Koneswaran S, Johnson DJ, Kelly RF, Ward HB, et al. Utility of N-acetylcysteine to prevent acute kidney injury after cardiac surgery: a randomized controlled trial. American heart journal. 2008;155:1143-9.

[44] Inda-Filho AJ, Caixeta A, Manggini M, Schor N. Do intravenous N-acetylcysteine and sodium bicarbonate prevent high osmolal contrast-induced acute kidney injury? A randomized controlled trial. PloS one. 
2014;9:e107602.

[45] Haase M, Haase-Fielitz A, Plass M, Kuppe H, Hetzer R, Hannon C, et al. Prophylactic perioperative sodium bicarbonate to prevent acute kidney injury following open heart surgery: a multicenter double-blinded randomized controlled trial. PLoS medicine. 2013;10:e1001426.

[46] Jang JS, Jin HY, Seo JS, Yang TH, Kim DK, Kim TH, et al. Sodium bicarbonate therapy for the prevention of contrast-induced acute kidney injury - a systematic review and meta-analysis. Circulation journal : official journal of the Japanese Circulation Society. 2012;76:2255-65.

[47] Tasanarong A, Duangchana S, Sumransurp S, Homvises B, Satdhabudha O. Prophylaxis with erythropoietin versus placebo reduces acute kidney injury and neutrophil gelatinase-associated lipocalin in patients undergoing cardiac surgery: a randomized, double-blind controlled trial. BMC nephrology. 2013;14:136.

[48] Shema-Didi L, Kristal B, Eizenberg S, Marzuq N, Sussan M, Feldman-Idov Y, et al. Prevention of contrast-induced nephropathy with single bolus erythropoietin in patients with diabetic kidney disease - A randomized controlled trial. Nephrology (Carlton, Vic). 2015/09/16 ed2015.

[49] Cai J, Xu R, Yu X, Fang Y, Ding X. Volatile anesthetics in preventing acute kidney injury after cardiac surgery: a systematic review and meta-analysis. The Journal of thoracic and cardiovascular surgery. 2014;148:3127-36.

[50] Freeland K, Hamidian Jahromi A, Duvall LM, Mancini MC. Postoperative blood transfusion is an independent predictor of acute kidney injury in cardiac surgery patients. Journal of nephropathology. 2015;4:121-6.

[51] Kanoria S, Jalan R, Seifalian AM, Williams R, Davidson BR. Protocols and mechanisms for remote ischemic preconditioning: a novel method for reducing ischemia reperfusion injury. Transplantation. 2007;84:445-58.

[52] Garg AX, Devereaux PJ, Yusuf S, Cuerden MS, Parikh CR, Coca SG, et al. Kidney function after off-pump or on-pump coronary artery bypass graft surgery: a randomized clinical trial. JAMA : the journal of the American Medical Association. 2014;311:2191-8. 
[53] Cheungpasitporn W, Thongprayoon C, Kittanamongkolchai W, Srivali N, OA OC, Edmonds PJ, et al. Comparison of Renal Outcomes in Off-Pump Versus On-Pump Coronary Artery Bypass Grafting: A Systematic Review and Meta-analysis of Randomized Controlled Trials. Nephrology (Carlton, Vic). 2015/05/15 ed2015. [54] Zhou S, Fang Z, Xiong H, Hu S, Xu B, Chen L, et al. Effect of one-stop hybrid coronary revascularization on postoperative renal function and bleeding: a comparison study with off-pump coronary artery bypass grafting surgery. The Journal of thoracic and cardiovascular surgery. 2014;147:1511-6 e1.

[55] Zhou C, Liu Y, Yao Y, Zhou S, Fang N, Wang W, et al. $\beta$-blockers and volatile anesthetics may attenuate cardioprotection by remote preconditioning in adult cardiac surgery: a meta-analysis of 15 randomized trials. Journal of cardiothoracic and vascular anesthesia. 2013;27:305-11.

\section{Figure legends:}

Figure 1. Searching process for the eligible studies. RCT, randomized controlled trial; CABG, coronary artery 
bypass graft; PCI, percutaneous coronary intervention.

Figure 2. Forest plot for in-hospital acute kidney injury(AKI) in elective CABG (A) or PCI (B).RIC, remote ischemic conditioning. Ctrl, control.

Figure 3. Forest plot for in-hospital AKI stage I (A) and requirement of renal replacement therapy(B) in elective CABG.. RIC, remote ischemic conditioning. Ctrl, control.

Figure 4. Forest plot for mortality in elective CABG.. RIC, remote ischemic conditioning. Ctrl, control. 
2193 relevant abstracts after literature search

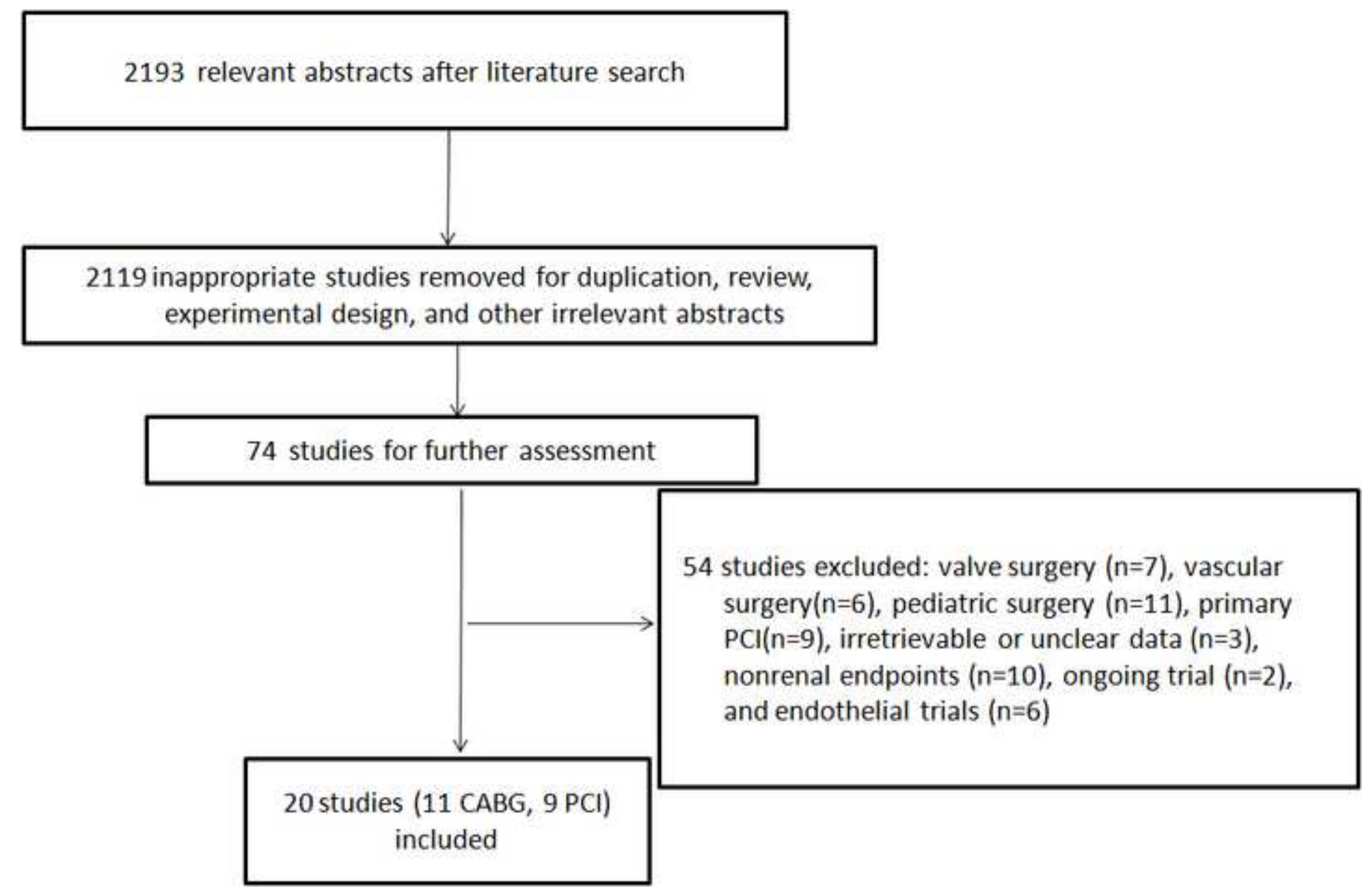


A

Study

ID

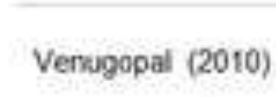

Rahman (2010)

Hong (2014)

Gallagher (2014)

Candito (2014)

Hausenloy (2015)

Zarbock (2015)

Young (2012)

Overall $(P=6.8 \% ; P=0.695)$

NOTE: Random-ffect Model

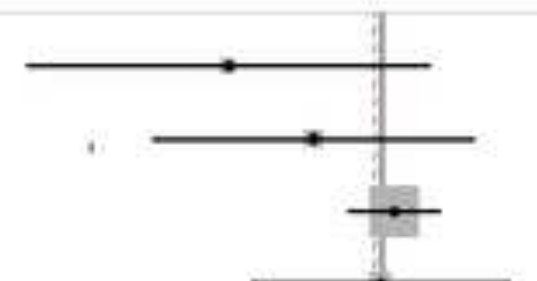

.05
Events.

OR $(95 \% \mathrm{Cl})$

RIC

Events.

Ctet

Weight

$\begin{array}{llll}0.33(0.08,1.43) & 3 / 35 & 7 / 32 & 2.37 \\ 0.62(0.19,1.98) & 5 / 75 & 8 / 77 & 3.65 \\ 1.10(0.79,1.54) & 118 / 267 & 121 / 289 & 35.99 \\ 1.00(0.39,2.57) & 12 / 43 & 12 / 43 & 5.53 \\ 0.38(0.12,1.17) & 5 / 57 & 11 / 54 & 3.87 \\ 1.04(0.77,1.41) & 130 / 395 & 123 / 395 & 43.03 \\ 0.74(0.29,1.90) & 13 / 44 & 13 / 36 & 5.56 \\ \text { (Excluded) } & 0 / 9 & 0.9 & 0.00\end{array}$

$0.96(0.76,1.20) \quad 286 / 925 \quad 295 / 925 \quad 100.00$

B

Study

ID

\begin{tabular}{|c|c|c|c|c|c|}
\hline Hoole (2009) & - & $0.54(0.19,1.54)$ & $6 / 104$ & $10 / 98$ & 1321 \\
\hline Er (2012) & & $0.20(0.07,0.57)$ & $6 / 50$ & $20 / 50$ & 1368 \\
\hline Igarashi (2012) & & $0.20(0.04,1.02)$ & $2 / 30$ & $8 / 30$ & 6.89 \\
\hline Deftereos (2013) & & $0.34(0.17,0.68)$ & $14 / 113$ & $33 / 112$ & 2065 \\
\hline Xu (2013) & & $129(0.28,5.93)$ & $4 / 102$ & $3 / 98$ & 780 \\
\hline Luo (2013) & & $2.08(0.19,23.31)$ & $2 / 101$ & $1 / 104$ & 3.56 \\
\hline Lavill $(2014)$ & + & $1.25(0.45,3.48)$ & $9 / 114$ & $7 / 109$ & 1366 \\
\hline Lavi (2014) & & $0.67(0.21,217)$ & $5 / 114$ & $7 / 109$ & 11.37 \\
\hline Savaj (2014) & & $0.18(0,02,1.63)$ & $1 / 48$ & $5 / 48$ & 4.28 \\
\hline Menting (2015) & & $1.00(0.13,7.49)$ & $2 / 36$ & $2 / 38$ & 4.92 \\
\hline Overall $\left(\mathbb{P}^{2}=29.6 \% ; P=0.006\right)$ & & $0.51(0.31,0.82)$ & $51 / 814$ & $96 / 796$ & 100.00 \\
\hline NOTE Random-ellect Model & & & & & \\
\hline 1 & 10 & & & & \\
\hline
\end{tabular}

Events, Events, \%

OR $(95 \% \mathrm{Cl})$ RIC Ctrl Weight 


\section{Figure 3}

Click here to download high resolution image

\section{A}

Study

Everts, Everes, 9

30

OR(35\% C1) RIC Ctr Weigh

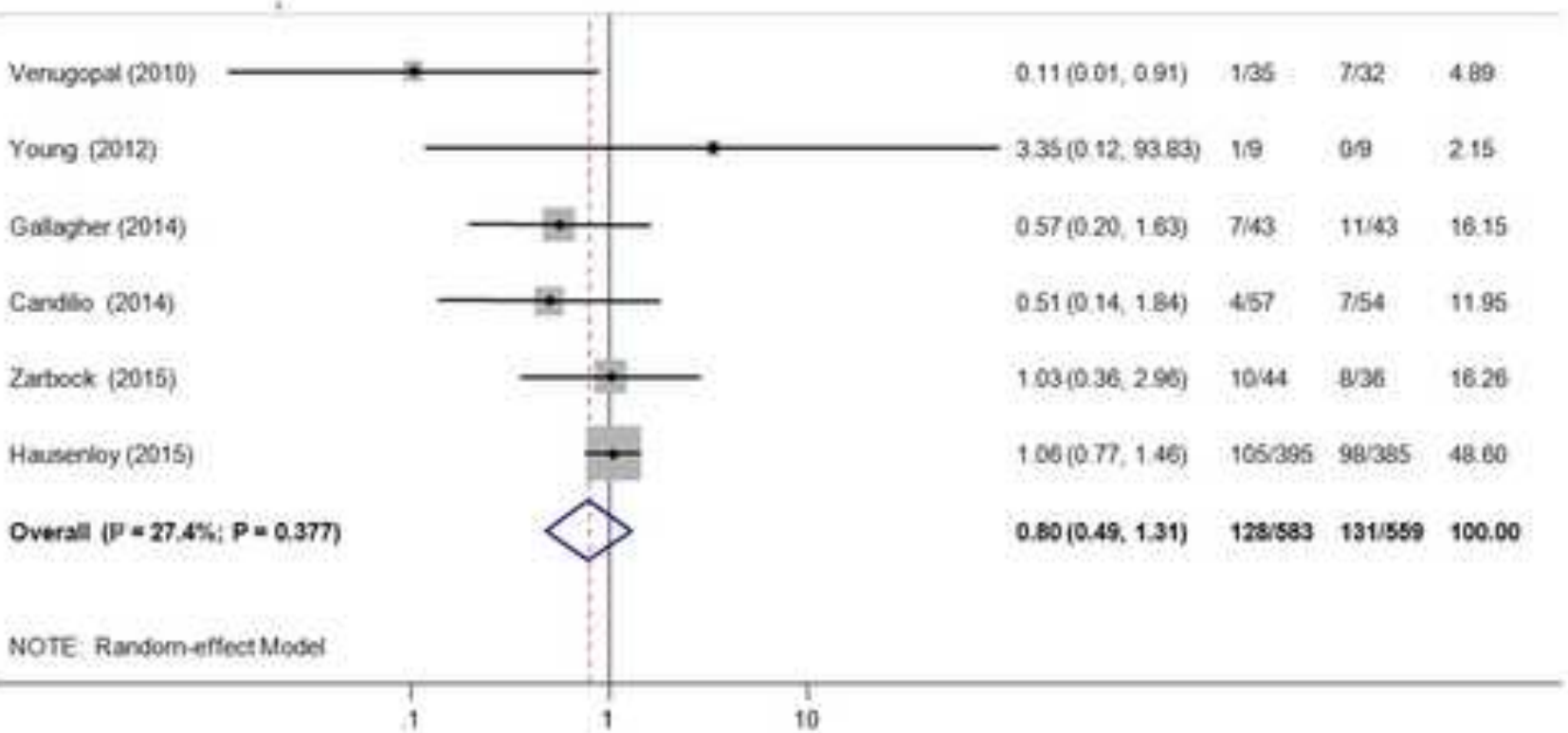

B

Soudy

ID

OR $(9 s \%$ Cn $)$ Ric Ctri Weight

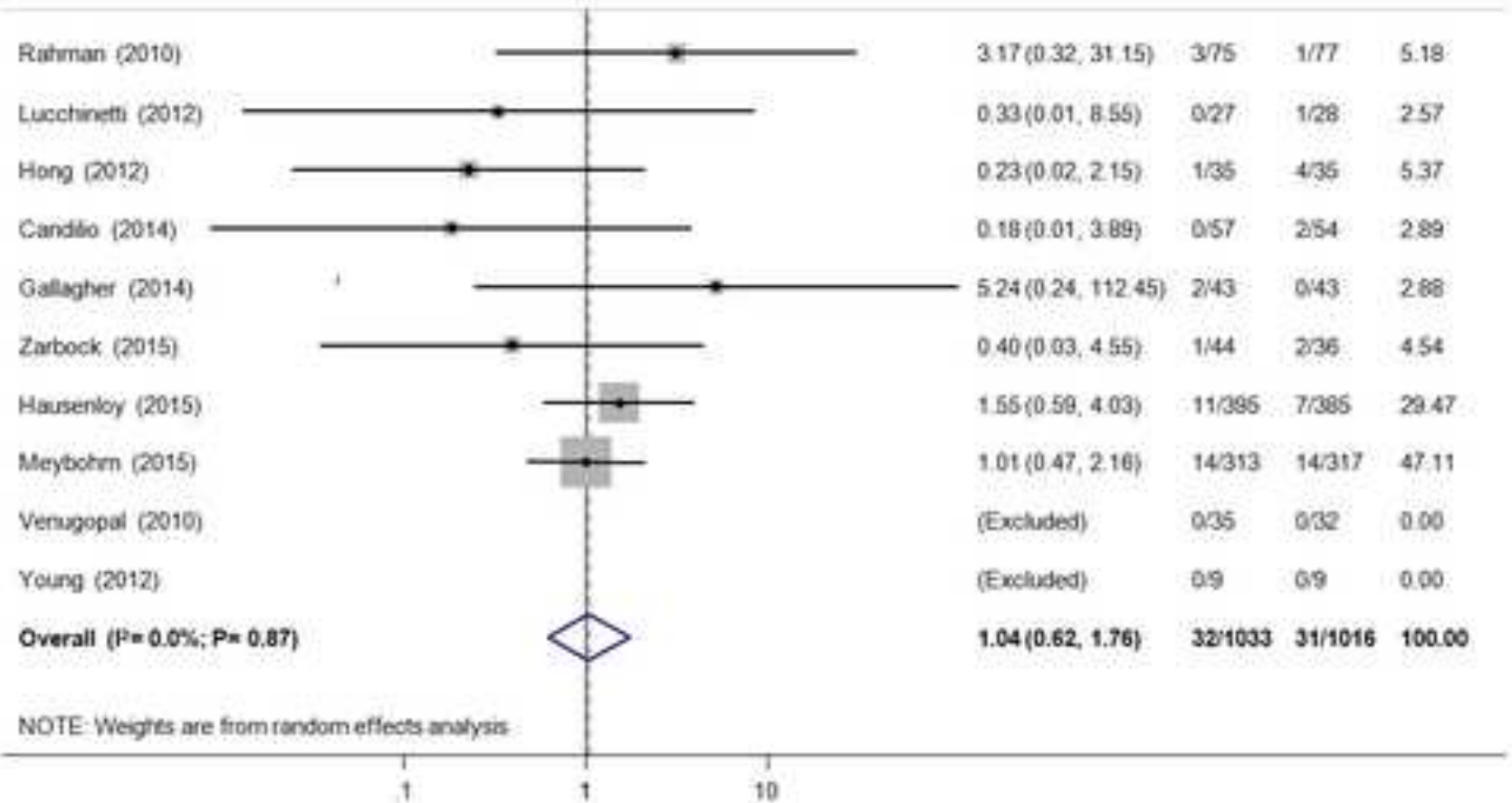


Click here to download high resolution image

Study

ID

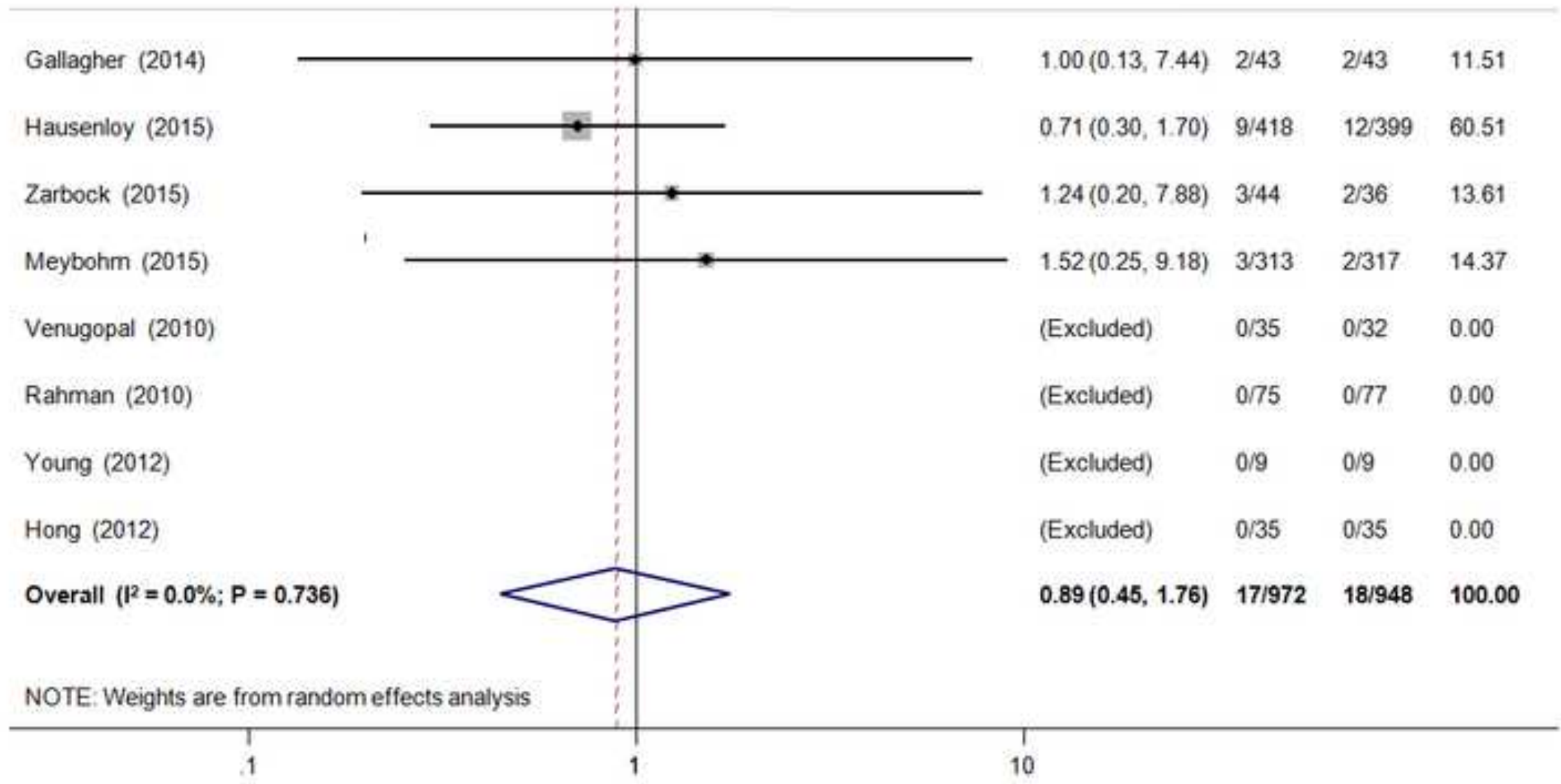

Events, Events, \%

OR $(95 \% \mathrm{Cl})$ RIC Ctrl Weight

$\begin{array}{llll}1.00(0.13,7.44) & 2 / 43 & 2 / 43 & 11.51 \\ 0.71(0.30,1.70) & 9 / 418 & 12 / 399 & 60.51 \\ 1.24(0.20,7.88) & 3 / 44 & 2 / 36 & 13.61 \\ 1.52(0.25,9.18) & 3 / 313 & 2 / 317 & 14.37 \\ \text { (Excluded) } & 0 / 35 & 0 / 32 & 0.00 \\ \text { (Excluded) } & 0 / 75 & 0 / 77 & 0.00 \\ \text { (Excluded) } & 0 / 9 & 0 / 9 & 0.00 \\ \text { (Excluded) } & 0 / 35 & 0 / 35 & 0.00 \\ \text { 0.89(0.45, 1.76) } & 17 / 972 & 18 / 948 & 100.00\end{array}$


Table 1 Study design in all included randomized trials

\begin{tabular}{|c|c|c|c|c|c|c|c|c|c|c|c|c|}
\hline \multirow[b]{2}{*}{ Study } & \multirow[t]{2}{*}{ Country } & \multirow[b]{2}{*}{ Surgery } & \multirow[b]{2}{*}{$\begin{array}{l}\text { Pts. No. } \\
\text { RIC vs Ctrl }\end{array}$} & \multicolumn{2}{|c|}{ RIC protocol } & \multirow[b]{2}{*}{$\begin{array}{l}\text { RIC initiation to } \\
\text { invasive procedure }\end{array}$} & \multirow[b]{2}{*}{$\begin{array}{l}\text { Placebo } \\
\text { Control }\end{array}$} & \multirow{2}{*}{$\begin{array}{c}\text { Renal } \\
\text { Endpoints }\end{array}$} & \multirow{2}{*}{$\begin{array}{c}\text { Baseline } \\
\text { Creatinine } \\
\text { level(mg/dl) }\end{array}$} & \multirow[b]{2}{*}{ AKI Definition } & \multirow[b]{2}{*}{ F-up } & \multirow[b]{2}{*}{$\begin{array}{l}\text { Jada } \\
\text { scor }\end{array}$} \\
\hline & & & & Cycles $x / / R$ & Cuff pressure & & & & & & & \\
\hline Rahman $2010^{[21]}$ & UK & $\mathrm{CABG}(\mathrm{On})$ & 42 vs 38 & $3 \times 5 \mathrm{~min} / 5 \mathrm{~min}$ at upper limb & $200 \mathrm{mmHg}$ & $74 \mathrm{mins}$ & Yes & AKI, RRT, Mortality & 1.10 & $\mathrm{SCr} \uparrow>0.5 \mathrm{mg} / \mathrm{dl}$ & $30 \mathrm{~d}$ & 5 \\
\hline Venugopal $2010^{[22]}$ & UK & $\mathrm{CABG}(\mathrm{On})$ & 35 vs 32 & $3 \times 5 \mathrm{~min} / 5 \mathrm{~min}$ at upper limb & $200 \mathrm{mmHg}$ & $<45 \sim 60 \mathrm{mins}$ & Yes & AKI,RRT,Mortality & 0.95 & $\mathrm{SCr} \uparrow \geqslant 50 \%$ or $\geqslant 0.3 \mathrm{mg} / \mathrm{dl}$ & $30 \mathrm{~d}$ & 4 \\
\hline Young $2012^{[3]]}$ & $\begin{array}{c}\text { New } \\
\text { Zealand }\end{array}$ & $\begin{array}{l}\text { CABG(On) } \\
\text { (Substudy) }\end{array}$ & 9 vs 9 & $3 \times 5 \min / 5 \min$ at upper limb & $200 \mathrm{mmHg}$ & N.A & Yes & AKI, RRT, Mortaltiy & 1.10 & SCr $\uparrow \geqslant 50 \%$ or eGFR $\downarrow \geqslant 25 \%$ & $30 \mathrm{~d}$ & 5 \\
\hline Lucchinetti $2012^{[34]}$ & Canada & $\mathrm{CABG}(\mathrm{On})$ & 27 vs 28 & $4 \times 5 \mathrm{~min} / 5 \mathrm{~min}$ at thigh & $300 \mathrm{mmHg}$ & N.A & Yes & RRT & 1.01 & RRT & 6 mon & 5 \\
\hline Hong $2012^{[35]}$ & Korea & $\mathrm{CABG}(\mathrm{Off})$ & 35 va 35 & $4 \times 5 \mathrm{~min} / 5 \mathrm{~min}$ at thigh & $200 \mathrm{mmHg}$ & $18 \mathrm{mins}$ & Yes & RRT, Mortality & 1.10 & RRT & $30 \mathrm{~d}$ & 3 \\
\hline Hong $2014^{[24]}$ & Korea & $\begin{array}{l}\text { CABG(Off) } \\
\text { (Substudy) }\end{array}$ & 267 vs 289 & $4 \times 5 \min / 5 \min$ at thigh & $200 \mathrm{mmHg}$ & N.A & Yes & AKI & N.A & $\mathrm{SCr} \uparrow \geqslant 50 \%$ or $\geqslant 0.3 \mathrm{mg} / \mathrm{dl}$ & In-hospital & 5 \\
\hline Gallagher $2014^{[23]}$ & UK & CABG & 43 vs 43 & $3 \times 5 \mathrm{~min} / 5 \mathrm{~min}$ at upper limb & $\begin{array}{c}50 \mathrm{mmHg}> \\
\text { SBP }\end{array}$ & N.A & Yes & AKI, RRT, Mortality & 1.37 & $\mathrm{SCr} \uparrow \geqslant 50 \%$ or $\geqslant 0.3 \mathrm{mg} / \mathrm{dl}$ & $30 \mathrm{~d}$ & 2 \\
\hline Candilio 2014 $4^{[3]}$ & UK & $\begin{array}{l}\text { CABG(On) } \\
\text { (Substudy) }\end{array}$ & 57 vs 54 & $2 \times 5 \mathrm{~min} / 5 \mathrm{~min}$ at upper limb and thigh & $200 \mathrm{mmHg}$ & $<45 \mathrm{mins}$ & Yes & AKI, RRT & N.A & $\mathrm{SCr} \uparrow \geqslant 50 \%$ or $\geqslant 0.3 \mathrm{mg} / \mathrm{dl}$ & In-hospital & 5 \\
\hline Hausenloy $2015^{[25]}$ & UK & $\begin{array}{l}\mathrm{CABG}(\mathrm{On}) \\
\text { (Substudy) }\end{array}$ & 395 vs 385 & $4 \times 5 \min / 5 \min$ at upper limb & $200 \mathrm{mmHg}$ & $105 \min$ & Yes & AKI, RRT, Mortality & N.A & $\mathrm{SCr} \uparrow \geqslant 50 \%$ or $\geqslant 0.3 \mathrm{mg} / \mathrm{dl}$ & In-hospital & 5 \\
\hline Zarbock $2015^{[30]}$ & German & $\begin{array}{l}\mathrm{CABG}(\mathrm{On}) \\
\text { (Substudy) }\end{array}$ & 44 vs 36 & $3 \times 5 \mathrm{~min} / 5 \min$ at upper limb & $\begin{array}{c}200 \mathrm{mmHg} \text { or } \\
50 \mathrm{mmHg}> \\
\mathrm{SBP}\end{array}$ & N.A & Yes & AKI, RRT, Mortality & 1.15 & $\mathrm{SCr} \uparrow \geqslant 50 \%$ or $\geqslant 0.3 \mathrm{mg} / \mathrm{dl}$ & In-hospital & 5 \\
\hline Meybohm $2015^{[26]}$ & German & $\begin{array}{l}\text { CABG(On) } \\
\text { (Substudy) }\end{array}$ & 313 vs 317 & $4 \times 5 \min / 5 \min$ at upper limb & $\begin{array}{c}\geqslant 200 \mathrm{mmHg} \\
\text { or } 15 \mathrm{mmHg}> \\
\mathrm{SBP}\end{array}$ & N.A & Yes & RRT, Mortality & N.A & $\mathrm{SCr} \uparrow \geqslant 50 \%$ or $\geqslant 0.3 \mathrm{mg} / \mathrm{dl}$ & In-hospital & 5 \\
\hline Hoole $2009^{[32]}$ & UK & $\mathrm{PCI}$ & 104 vs 98 & $3 \times 5 \min / 5 \min$ at upper limb & $200 \mathrm{mmHg}$ & $96.0 \mathrm{mins}$ & Yes & AKI & N.A & $\mathrm{SCr} \uparrow>25 \%$ & $24 \mathrm{~h}$ & 4 \\
\hline Er 2012 & Germany & $\mathrm{PCI}$ & 50 vs 50 & $4 \times 5 \min / 5 \min$ at upper limb & $\begin{array}{c}50 \mathrm{mmHg}> \\
\text { SBP }\end{array}$ & 40.0 to $85.0 \mathrm{mins}$ & Yes & AKI & 1.63 & $\mathrm{SCr} \uparrow \geqslant 25 \%$ or $\geqslant 0.5 \mathrm{mg} / \mathrm{dl}$ & $48 \mathrm{~h}$ & 5 \\
\hline Igarashi $2013^{[33]}$ & Japan & PCI & 30 vs30 & $4 \times 5 \min / 5 \min$ at upper limb & $200 \mathrm{mmHg}$ & $120 \mathrm{~min}$ & No & AKI & 1.13 & Urinary L-FABP $\uparrow>25 \%$ or $>17.4 \mu \mathrm{g} / \mathrm{g} \mathrm{SCr}$ & $48 \mathrm{~h}$ & 3 \\
\hline Luo $2013^{(40]}$ & China & $\mathrm{PCI}$ & 101 vs 104 & $3 \times 5 \mathrm{~min} / 5 \min$ at upper limb & $200 \mathrm{mmHg}$ & $<120.0 \mathrm{mins}$ & Yes & AKI & N.A & $\operatorname{SCr} \uparrow>25 \%$ & $16 \mathrm{~h}$ & 3 \\
\hline Deftereos $2013^{[27]}$ & Greece & $\mathrm{PCI}$ & 113 vs 112 & $4 \times 30 s / 30$ s at heart & $<3 \mathrm{~atm}$ & Immediately & Yes & AKI & 1.0 & $\mathrm{SCr} \uparrow \geqslant 25 \%$ or $\geqslant 0.5 \mathrm{mg} / \mathrm{dl}$ & $96 \mathrm{~h}$ & 3 \\
\hline Xu $2013^{[3]}$ & China & $\mathrm{PCI}$ & 102 vs 98 & $3 \times 5 \mathrm{~min} / 5 \mathrm{~min}$ at upper limb & $200 \mathrm{mmHg}$ & 30.0 to $120.0 \mathrm{mins}$ & No & AKI & 0.86 & $\mathrm{SCr} \uparrow>25 \%$ & $16 \mathrm{~h}$ & 5 \\
\hline Savaj $2014^{[38]}$ & Iran & $\mathrm{PCI}$ & 48 vs 48 & $3 \times 5 \min / 5 \min$ at upper limb & $200 \mathrm{mmHg}$ & 15 mins & No & AKI & 1.19 & $\mathrm{SCr} \uparrow \geqslant 30 \%$ or $\geqslant 0.3 \mathrm{mg} / \mathrm{dl}$ & $24 \mathrm{~h}$ & 1 \\
\hline Lavi $2014 \mathrm{I}^{[28]}$ & Canada & $\mathrm{PCI}$ & 120 vs 120 & $3 \times 5 \mathrm{~min} / 5 \mathrm{~min}$ at upper limb & $\begin{array}{c}200 \mathrm{mmHg} \text { or } \\
50 \mathrm{mmHg}> \\
\text { SBP }\end{array}$ & $\begin{array}{l}\text { Several mins after } \\
\text { PCI }\end{array}$ & Yes & AKI & N.A & $\mathrm{SCr} \uparrow>25 \%$ or $>0.5 \mathrm{mg} / \mathrm{dl}$ & $24 \mathrm{~h}$ & 5 \\
\hline Lavi 2014 I[ $^{[28]}$ & Canada & $\mathrm{PCI}$ & 120 vs 120 & $3 \times 5 \mathrm{~min} / 5 \mathrm{~min}$ at thigh & $\begin{array}{c}200 \mathrm{mmHg} \text { or } \\
50 \mathrm{mmHg}> \\
\text { SBP }\end{array}$ & $\begin{array}{l}\text { Several mins after } \\
\text { PCI }\end{array}$ & Yes & AKI & N.A & $\mathrm{SCr} \uparrow>25 \%$ or $>0.5 \mathrm{mg} / \mathrm{dl}$ & $24 \mathrm{~h}$ & 5 \\
\hline
\end{tabular}


Table 2 Patient characteristics in all included randomized trials

\begin{tabular}{|c|c|c|c|c|c|c|c|c|c|c|c|c|c|}
\hline Substudy & Age & $\begin{array}{l}\text { Male( } \\
\%)\end{array}$ & $\begin{array}{c}\text { Pre-MI } \\
(\%)\end{array}$ & $\begin{array}{l}\text { DM } \\
(\%)\end{array}$ & $\begin{array}{l}\text { HT } \\
(\%)\end{array}$ & $\begin{array}{c}\text { Dyslipid } \\
\text { emia } \\
(\%)\end{array}$ & $\begin{array}{c}\text { Renal } \\
\text { dysfunction } \\
(\%)\end{array}$ & $\begin{array}{c}\text { CPB } \\
\text { duration } \\
(\min )\end{array}$ & $\begin{array}{l}\text { Contrast } \\
\text { Dose }(m \mathrm{~m})\end{array}$ & $\begin{array}{c}\text { Baseline } \\
\text { LVEF(\%) }\end{array}$ & $\begin{array}{c}\text { Target } \\
\text { Vessels } \geq 2 \\
(\%)\end{array}$ & $\begin{array}{c}\beta \text {-blockers } \\
(\%)\end{array}$ & $\begin{array}{c}\text { Statins } \\
(\%)\end{array}$ \\
\hline Rahman $2010^{[21]}$ & 64.0 & 88.5 & 0.0 & 0.0 & 59.3 & 74.1 & N.A & 98 & l & 60.1 & 100.0 & 81.0 & 88.0 \\
\hline Venugopal $2010^{[22]}$ & 65.0 & 82.0 & 23.0 & 0.0 & 65.4 & 75.6 & N.A & 86 & I & N.A & 96 & 55 & 79.5 \\
\hline Young $2012^{[31]}$ & 66.4 & 62.5 & 27.8 & N.A & N.A & 60.4 & N.A & 111.1 & l & N.A & 57.3 & 66.7 & 60.4 \\
\hline Lucchinetti $2012^{[34]}$ & 60.5 & 91.0 & 41.8 & 0.0 & 70.9 & 85.5 & N.A & 101 & l & 52.0 & 100.0 & 91.0 & 96.0 \\
\hline Hong $2012^{[35]}$ & 64.7 & 72.9 & N.R & 35.7 & 68.6 & 17.1 & 0 & 54 & I & $\geq 30.0$ & 100.0 & 64.3 & 72.9 \\
\hline Hong $2014^{[24]}$ & 60.8 & 61.3 & 7.3 & 30.2 & 48.6 & 53.8 & 3.1 & 159.7 & I & 57 & N.A & 42.7 & N.A \\
\hline Gallagher $2014^{[23]}$ & 70.8 & 80.2 & 52.3 & 64.0 & 82.6 & 77.9 & N.A & 94 & l & 52 & 96.5 & 35 & 91.9 \\
\hline Candilio $2014^{[36]}$ & 65.5 & 78.1 & 28.7 & 29.2 & 78.8 & 74.2 & 0 & 93.2 & I & N.A & 93.1 & 74.2 & 80.9 \\
\hline Hausenloy $2015^{[25]}$ & 76.2 & 70.8 & 39.5 & 25.7 & 74.5 & 69.8 & 0 & 70.0 & l & N.A & N.A & N.A & N.A \\
\hline Zarbock $2015^{[30]}$ & 70.4 & 62.9 & 0 & 37.5 & 96.7 & N.A & 30.9 & 118 & I & N.A & N.A & 73.0 & 82.5 \\
\hline Meybohm 2015 $5^{[26]}$ & 66.0 & 74.2 & 28.9 & 24.8 & N.A & N.A & 11.2 & N.A & l & N.A & N.A & 63.2 & 65.5 \\
\hline Hoole $2009^{[32]}$ & 62.5 & 78.2 & 55.4 & 21.8 & 51.5 & N.A & N.A & I & 192.2 & 50.2 & 16.8 & 79.2 & 95.0 \\
\hline Er 2012 $2^{[41]}$ & 71.1 & 71.7 & N.A & 33.3 & N.A & N.A & $\begin{array}{c}\text { eGFR:30 60 } \\
(48.2)\end{array}$ & l & 92.4 & N.A & N.A & 43.3 & 75.0 \\
\hline Igarashi $2013^{[33]}$ & 73.0 & 71.0 & 41.0 & 64.0 & 91 & 75.0 & $\begin{array}{l}\text { eGFR< } \\
60(38.3)\end{array}$ & l & 113.5 & 59.6 & N.A & 82.0 & N.A \\
\hline Luo $2013^{[40]}$ & 59.3 & 76.1 & 21.5 & 27.8 & 65.9 & N.A & $\mathrm{eGFR}=100$ & l & 149.4 & 64.0 & 27.8 & 82.4 & N.A \\
\hline Deftereos $2013^{[27]}$ & 68 & 64.0 & N.A & 36 & 65 & 59 & $\begin{array}{c}e G F R>60(75 \\
)\end{array}$ & I & 270 & 56 & 55.1 & 17 & 36 \\
\hline $\mathrm{Xu} 2013^{[37]}$ & 69.0 & 68.0 & 23.0 & 100.0 & 63.5 & N.A & eGFR=99.9 & I & 167.6 & 63.7 & N.A & 80.0 & 100.0 \\
\hline Savaj 2014 $4^{[38]}$ & 62 & 32.3 & 16.7 & 100 & 70.9 & N.A & $\begin{array}{c}\mathrm{eGFR}>50(86 \\
.5)\end{array}$ & I & 125.2 & N.A & N.A & N.A & N.A \\
\hline Lavi $2014 \mathrm{I}^{[28]}$ & 63.7 & 72.9 & 43.0 & 32.5 & 70.0 & 67.0 & $\mathrm{eGFR}>30$ & l & 187.5 & N.A & 18.8 & N.A & N.A \\
\hline Lavi 2014 II $^{[28]}$ & 64.3 & 74.2 & 42.0 & 29.5 & 70.0 & 65.0 & eGFR $>30$ & I & 187.5 & N.A & 21.67 & N.A & N.A \\
\hline Menting $2015^{[39]}$ & 72 & 48.5 & 40 & 25 & 72.5 & N.A & $\mathrm{eGFR}=51$ & I & 98.5 & N.A & N.A & 65.5 & N.A \\
\hline
\end{tabular}

Note: Pre-MI, previous myocardial infarction; DM, diabetes mellitus; HT, hypertension; CPB, cardiopulmonary bypass; eGFR, estimated glomerular filtration rate; LVEF, left ventricular ejection fraction; N.A, not 